\title{
Epidemiologic Profile of Maternal Deaths in Two Referral Hospitals in Cameroon
}

\author{
Philip Njotang Nana1,2, Felix Essiben ${ }^{1,2 *}$, Julius Dohbit Sama ${ }^{1,3}$, Elisabeth Medoua Koh Koh4, \\ Morfaw Lifanji ${ }^{5}$, Filbert Eko Eko², Jeanne Fouedjio ${ }^{1,2}$, Agnes Esiene ${ }^{2,6}$, \\ Robinson Enow Mbu1,2 \\ ${ }^{1}$ Department of Obstetrics and Gynecology, Faculty of Medicine and Biomedical Sciences (FMBS), The \\ University of Yaoundé I, Yaoundé, Cameroon \\ ${ }^{2}$ Department of Obstetrics and Gynecology, Yaoundé Central Hospital, Yaoundé, Cameroon \\ ${ }^{3}$ Department of Obstetrics and Gynecology, Yaoundé Gyneco-Obstetric and Pediatric Hospital, Yaoundé, \\ Cameroon \\ ${ }^{4}$ Faculty of Medicine and Biomedical Sciences (FMBS), The University of Yaoundé I, Yaoundé, Cameroon \\ ${ }^{5}$ Department of Obstetrics and Gynecology, Bamenda Regional Hospital, Bamenda, Cameroon \\ ${ }^{6}$ Department of Anesthesia and Reanimation, Faculty of Medicine and Biomedical Sciences (FMBS), The \\ University of Yaoundé I, Yaoundé, Cameroon \\ Email: "essibenx@yahoo.com
}

Received 5 April 2016; accepted 15 May 2016; published 18 May 2016

Copyright (c) 2016 by authors and Scientific Research Publishing Inc.

This work is licensed under the Creative Commons Attribution International License (CC BY).

http://creativecommons.org/licenses/by/4.0/

(c) $\underset{\mathrm{EY}}{\mathrm{C}}$ Open Access

\section{Abstract}

Introduction: Our objective was to compare the epidemiologic profile of maternal mortality in two structures serving as referral levels of care in Cameroon. Methodology: This cross-sectional, comparative study took place at the maternities of the Yaoundé Central Hospital (YCH) and the Bamenda Regional Hospital (BRH) from December 1st 2014 to May 31st 2015, a 6 months' period. The medical records of deceased women over 5 years, from January 2010 to December 2014, were collected. We calculated the MMR (Maternal mortality rate) and studied the causes and risk factors associated with maternal death. The Epi info software 3.5.4 was used to analyze data with a significance level of $P<0.05$. Results: The maternal mortality ratio (MMR) was 964 and 247 per 100,000 live births for YCH and BRH, respectively. More deaths occurred within the aged group range 20 to 34 years, $76.8 \%$ at $\mathrm{YCH}$ and $64.7 \%$ at $\mathrm{BRH}$. At $\mathrm{YCH}, 70.7 \%$ of these patients were referrals versus $32.4 \%$ at $B R H$. Complication from abortion was often implicated at $B R H(P=0.007$; $\mathrm{OR}=0.31 ; \mathrm{CI}=0.13-0.74)$. Others causes were hemorrhage ( $\mathrm{YCH}=43.4 \%$; $\mathrm{BRH}=35.5 \%$ ), hypertensive diseases $(\mathrm{YCH}=17.2 \%$; $\mathrm{BRH}=14.7 \%)$ and infections $(\mathrm{YCH}=8.1 \%$; $\mathrm{BRH}=17.6 \%)$. At $\mathrm{YCH}$ time elapsed from admission to death was $<3 \mathrm{~h}(\mathrm{P}=0.005 ; \mathrm{OR}=6.63 ; \mathrm{CI}=1.49-29.5)$. Conclusion: Both hospitals have similar causes of maternal deaths, differing only in the context within which

${ }^{*}$ Corresponding author.

How to cite this paper: Nana, P.N., Essiben, F., Sama, J.D., Koh Koh, E.M., Lifanji, M., Eko, F.E., Fouedjio, J., Esiene, A. and Mbu, R.E. (2016) Epidemiologic Profile of Maternal Deaths in Two Referral Hospitals in Cameroon. Open Journal of Obstetrics and Gynecology, 6, 365-372. http://dx.doi.org/10.4236/ojog.2016.66047 
the deaths occurred. Improving access to good quality health care, satisfying unmet needs for family planning, availability of blood products and the establishment of health insurance could decrease the maternal mortality rate.

\title{
Keywords
}

\author{
Maternal Mortality, Causes, Maternal Death, Referral Hospital, Cameroon
}

\section{Introduction}

Maternal mortality is an indicator of the quality of the healthcare system in a country or a region thereof. Maternal death is a tragedy since it occurs most of the time, at the end of a normal process. According to WHO [1], 830 women die each day from preventable causes associated with pregnancy and delivery, and $99 \%$ of these deaths occur in developing countries.

Maternal mortality remains a major public health issue despite the disparities in the different regions of the world. The maternal mortality ratio is 16 per 100,000 and 230 per 100,000 live births in industrialized and developing countries, respectively [2]. However, Sub-Sahara Africa has the world's highest maternal mortality rate at 510 deaths per 100,000 live births [2].

Cameroon has one of the world's highest maternal mortality ratio, occupying the $9^{\text {th }}$ position worldwide [3]. Though was observed a 44\% decrease between 1990 and 2015 at the global level [1], the maternal mortality rate has steadily risen in Cameroon despite the increase number of strategies proposed by the government to crush maternal mortality. It rose from 430 to 782 per 100,000 live births from 1998 to 2014 [4].

Most of the causes of maternal deaths are known and are preventable [2] [5] [6]. In 1987, WHO developed an initiative of risk-free birthing aimed at reducing MMR. One of the four features of this initiative is accessibility to emergency obstetrical and neonatal care. Delay in administering emergency care is a determining factor in the fight against MM in a hospital setting [7] [8].

Maternal deaths occur in hospital settings as well as in the community. However, only hospital data are used in assessing the scope of the problem. The level of maternal deaths may shed light on the inequalities in accessing health care services, and deficiencies in the healthcare system [1], and thus guide strategic interventions aimed at reducing the MMR.

All levels of the healthcare pyramid are involved in the fight against MM. By studying the factors influencing MM, we will better appreciate the work still needed to deflect the MM curve. The goal of this study was to compare the epidemiologic profiles of maternal deaths in a regional hospital to a central hospital, both of which, are reference hospitals of the same levels.

\section{Methods}

It was a retrospective, cross-sectional and comparative study which lasted over 6 months, from $1^{\text {st }}$ December 2014 to $31^{\text {st }}$ May 2015, at the maternity of Yaoundé Central Hospital (HCY) and in the Department of Obstetrics and Gynecology of the Bamenda Regional Hospital (BRY). YCH even though has the Regional status, is one of the four University Teaching Hospitals in Yaoundé, the political capital of Cameroon. Its geographical location and accessibility to care, place it at the forefront of health care facilities in this town. BRH, located about 360 $\mathrm{km}$ from Yaoundé, is a Regional hospital with the highest level of care in the region. It has 02 obstetriciangynecologists and average technical standards. Both hospitals have all the professional grade working within.

After obtaining appropriate consent for our study, we collected medical records of all women who died over a 5-year period in the aforementioned departments from January 2010 to December 2014.

The records included women who died during pregnancy, delivery or postpartum. We also documented the number of live births during the same period. Our study excluded medical records of deceased women who had no evidence of pregnancy.

The variables studied were: age, level of education, matrimonial status, profession, gravid state, parity, number of prenatal consultations, gestational age at time of death, type of admission, admission diagnosis, overall well-being on admission, mode of delivery, fate of neonate, location of delivery, time elapsed from admission to 
death, causes of death (direct and indirect).

Data were analyzed using Epi Info software version 3.5.4. Results for quantitative variables were presented as mean ( \pm standard deviation) versus frequencies for qualitative variables. Comparative analyses were done using Fisher Exact and Chi-square tests. The difference was statistically significant for $\mathrm{P}<0.05$. The measure of association used odds ratio (OR) with its confidence interval (CI) set at 95\%.

\section{Results}

During the period of study, 173 maternal deaths and 17943 live births were registered at the YCH, giving a maternal mortality ratio of 964/100 000 live births. During the same period 41 maternal deaths and 16596 live births were reported at the BRH, giving a maternal mortality ratio of 247/100 000 live births (Table 1).

Our final analysis included 99 medical records from YCH (99/173; 57.2\%) and 34 from BRH (34/41; 82.9\%). Patients' ages varied between 16 and 43 years with a mean age of $27.9 \pm 6.3$; $28.4 \pm 7.1$ and $27.2 \pm 5.9$ years in Yaoundé and Bamenda, respectively. The age group 20 to 34 years was most represented, $76.8 \%$ at YCH and $64.7 \%$ at BRH. Women with a secondary education level were mostly implicated (54.8\%). At BRH, the death toll was highest among married women $(\mathrm{P}=0.002$; $\mathrm{OR}=0.27$; $\mathrm{CI}=0.11-0.65)$. Maternal age, level of education, matrimonial status, profession, gravid state, parity, and number of prenatal consultations done were similar in both hospitals (Table 2).

Place of delivery, fate of neonate and admission diagnosis were similar in both hospitals (Table 3).

There were more deaths prior to 28 weeks gestation at $\mathrm{BRH}(\mathrm{P}=0.007$; $\mathrm{OR}=0.31 ; \mathrm{CI}=0.13-0.74)$. More deaths occurred less than $3 \mathrm{~h}$ from admission at $\mathrm{YCH}(\mathrm{P}=0.005$; $\mathrm{OR}=6.63$; $\mathrm{CI}=1.49-29.5)$ (Table 4).

Death related to medical causes were comparable in both hospitals (Table 5).

Of the direct causes of death at BRH shown in Figure 1, post-abortal sepsis was contributory (6/25; 24\%). This is contrary to YCH where deaths resulting from post-abortal sepsis and puerperal sepsis were seen, $6.9 \%$ (5/72) and 4.2\% (3/72) respectively. Disseminated Intravascular Coagulation was a frequent cause of death at YCH (12/72; 16.7\%) as compared to $4 \%(1 / 25 ;)$ found at BRH. Uterine rupture was not registered as a cause of death at $\mathrm{BRH}$ versus $5(5 / 72 ; 6.9 \%)$ at $\mathrm{YCH}$.

\section{Discussion}

Our study showed that the maternal mortality ratio (MMR) was 3.9 times higher at YCH (964/100,000 live births) than at BRH (247/100,000 live births). In India and Nigeria several authors report MMR between 90 and 151 per 100,000 live births [6] [9] [10]. Yaoundé is more cosmopolitan than Bamenda. This cultural differences may influence patient care.

The high MMR at YCH is due to the high number of referred cases received, 70.7\% of deceased women were referred versus $32.4 \%$ at BRH. This finding could be supported by the fact that referred women arrived at YCH in a hemodynamically compromised state, and more died 3 hours after arrival at $\mathrm{YCH}$ than $\mathrm{BRH}, 29.3 \%$ and $5.9 \%$ respectively. FOMULU et al. [11] found that $82.05 \%$ of women who died were referred from other healthcare facilities. Tort et al. [12] showed that referred cases increased the risk of death 13 fold in cases of post-partum hemorrhage.

Table 1. Maternal mortality rate from 2010 to 2014 at YCH and BRH.

\begin{tabular}{|c|c|c|c|c|c|c|}
\hline \multirow[b]{2}{*}{ Year } & \multicolumn{3}{|c|}{ Yaoundé Central Hospital } & \multicolumn{3}{|c|}{ Bamenda Regional Hospital } \\
\hline & $\begin{array}{c}\text { Number of live } \\
\text { births }\end{array}$ & $\begin{array}{c}\text { Number of } \\
\text { deaths }\end{array}$ & MMR & $\begin{array}{c}\text { Number of live } \\
\text { births }\end{array}$ & $\begin{array}{c}\text { Number of } \\
\text { deaths }\end{array}$ & MMR \\
\hline 2010 & 3463 & 42 & 1212.8 & 3204 & 8 & 249.7 \\
\hline 2011 & 3300 & 38 & 1151.5 & 3228 & 8 & 247.8 \\
\hline 2012 & 3673 & 27 & 735.1 & 3313 & 4 & 120.7 \\
\hline 2013 & 3666 & 37 & 1009.3 & 3203 & 8 & 249.8 \\
\hline 2014 & 3841 & 29 & 755.0 & 3648 & 13 & 356.4 \\
\hline Total & 17943 & 173 & 964.2 & 16596 & 41 & 247.1 \\
\hline
\end{tabular}


Table 2. Socio-demographic characteristics of deceased women at YCH and BRH. 2010-2014.

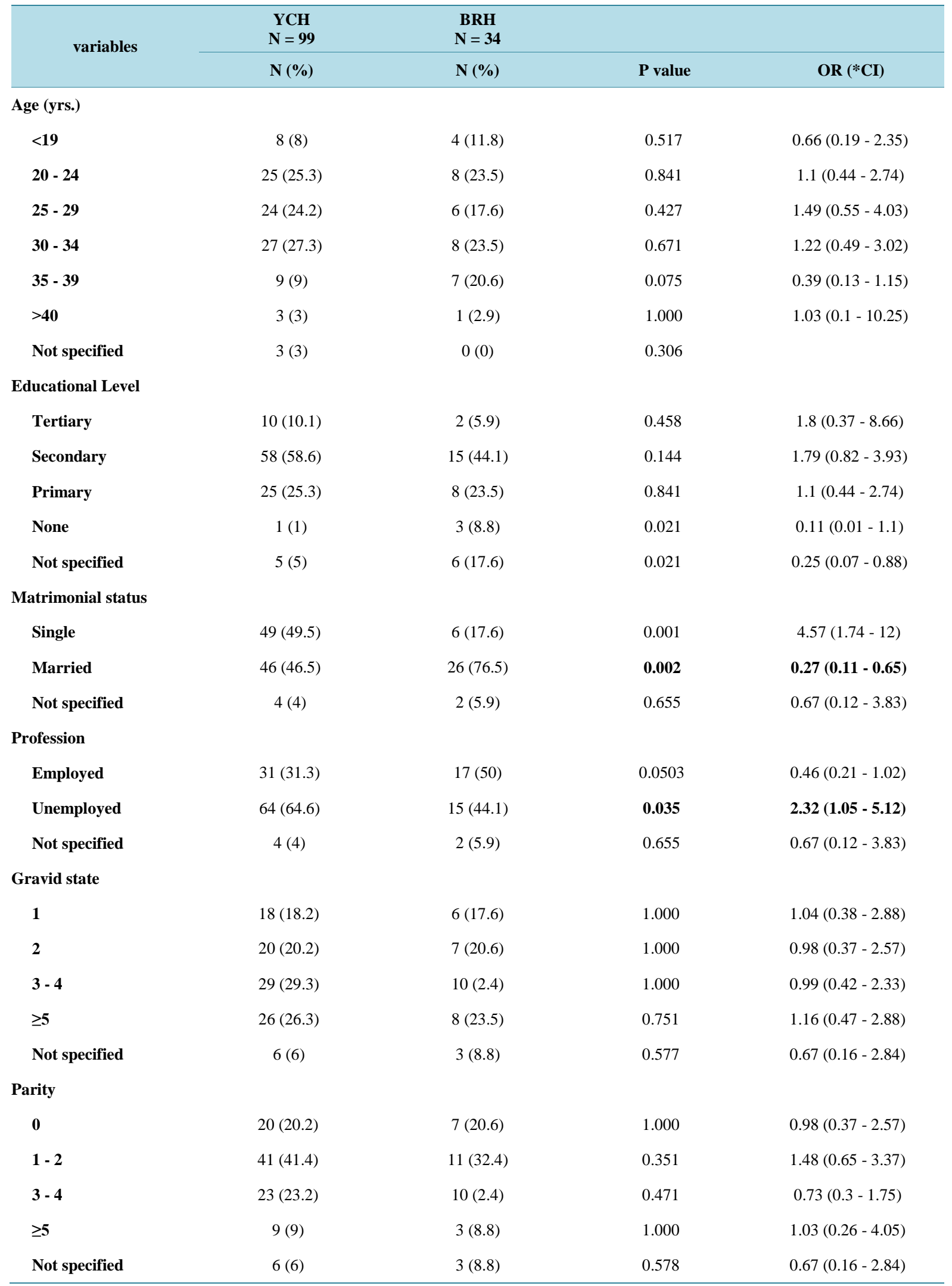




\begin{tabular}{lcccc} 
Continued & & & \\
\hline PNC & $21(21.2)$ & $10(2.4)$ & 0.330 & $0.65(0.27-1.57)$ \\
$\mathbf{0}$ & $5(5)$ & $2(5.6)$ & 0.841 & $0.85(0.16-4.6)$ \\
$\mathbf{1}$ & $16(16.2)$ & $2(5.6)$ & 0.130 & $3.08(0.67-14.16)$ \\
$\mathbf{2}$ & $18(18.2)$ & $4(11.8)$ & 0.386 & $1.67(0.52-5.34)$ \\
$\mathbf{3}$ & $11(11.1)$ & $3(8.8)$ & 0.708 & $1.29(0.34-4.93)$ \\
$\mathbf{4}$ & $12(12.1)$ & $7(20.6)$ & 0.224 & $0.53(0.19-1.48)$ \\
$\mathbf{2}$ & $16(16.2)$ & $6(17.6)$ & 0.841 & $0.9(0.32-2.52)$ \\
Not specified & &
\end{tabular}

\%: percentage; OR: Odds Ratio; CI: confidence interval.

Table 3. Admission diagnosis of deceased women at YCH and BRH. 2010-2014.

\begin{tabular}{|c|c|c|c|c|}
\hline Variables & $\begin{array}{c}\text { YCH } \\
\text { N }=99 \\
\text { N (\%) }\end{array}$ & $\begin{array}{c}\text { BRH } \\
\text { N = 34 } \\
\text { N (\%) }\end{array}$ & $P$ value & OR (CI) \\
\hline \multicolumn{5}{|l|}{ Referred patients } \\
\hline Yes & $70(70.7)$ & $11(32.4)$ & 0.000 & $5.05(2.18-11.68)$ \\
\hline No & 29 (29.3) & $23(67.6)$ & & $0.2(0.09-0.46)$ \\
\hline Emergency admissions & $55(55.6)$ & $15(44.1)$ & 0.249 & $1.58(0.72-3.46)$ \\
\hline Post-partum hemorrhage & $18(18.2)$ & $1(2.9)$ & 0.028 & $7.33(0.94-57.17)$ \\
\hline Abortion & $11(11.1)$ & $8(23.5)$ & 0.074 & $0.41(0.15-1.13)$ \\
\hline Hypertensive disease & $17(17.2)$ & $5(14.7)$ & 0.740 & $1.2(0.41-3.55)$ \\
\hline Antepartum hemorrhage & $9(9.1)$ & $1(2.9)$ & 0.240 & $3.3(0.4-27.06)$ \\
\hline Non-emergency admissions & $44(44.4)$ & 19 (55.9) & 0.249 & $0.63(0.29-1.38)$ \\
\hline
\end{tabular}

\%: percentage; OR: Odds Ratio; CI: confidence interval.

Death occurred within 24 hours of admission at the YCH (75.6\%) as against 58.9\% at BRH. Other authors found rates similar to the latter [6] [10]. Limited resources for resuscitation, such as, oxygen in the emergency unit, emergency crash carts, a proficient emergency medical team and lack of blood products could explain the time lapse from arrival to death at YCH. Untimely referrals and delay in management have also been reported in the literature [7] [10].

Most women died in the post-partum with $83.8 \%$ occurring at $\mathrm{YCH}$ versus $61.8 \%$ at BRH. There were more deaths post-abortum at BRH, 38.2\%. This can be explained by the fact that in Bamenda, most of these abortions are unsafe and believed to be done by drug vendors. Children out of wedlock is still frowned upon. Unwanted pregnancies, low level of education and socio-economic status place these women at higher risk of illicit pregnancy termination.

Similar to TU AGAN et al. [6], more deaths occurred between ages 20 and 34 years, $76.8 \%$ at $\mathrm{YCH}$ and $64.7 \%$ at BRH. Other authors reported death occurring in older women [10]. Compared to BRH, women who died at YCH had at least a secondary level of education (68.7\%), a more superior level than those at BRH, where only half of them had this level of education.

There were more married women at BRH (76.5\%) than at YCH where single women were more representative (49.5\%). Cohabitation is more frequently seen in rural settings. Maternal deaths occur more often in married women [6]. Most of the women who died at YCH were unemployed (64.6\%) versus $44.11 \%$ at BRH. Financial constraints contributed to the delay in management at $\mathrm{YCH}$ since patients and their families were to pay for all the costs of care upon arrival. Delay in management is usually incriminated as cause of death in hospital settings [6]. 
Table 4. Risk factors associated with maternal deaths at YCH and BRH. 2010-2014.

\begin{tabular}{|c|c|c|c|c|}
\hline \multirow{2}{*}{ Variables } & $\begin{array}{c}\text { YCH } \\
\mathbf{N}=99\end{array}$ & $\begin{array}{c}\text { BRH } \\
\mathbf{N}=\mathbf{3 4}\end{array}$ & \multirow[b]{2}{*}{$P$ value } & \multirow[b]{2}{*}{ OR (CI) } \\
\hline & N (\%) & N (\%) & & \\
\hline \multicolumn{5}{|l|}{ Referred patients } \\
\hline Yes & $70(70.7)$ & $11(32.4)$ & 0.000 & $5.05(2.18-11.68)$ \\
\hline No & $29(29.3)$ & $23(67.6)$ & & $0.2(0.09-0.46)$ \\
\hline \multicolumn{5}{|c|}{ Gestational age at time of death (weeks) } \\
\hline Post abortum & $16(16.2)$ & $13(38.2)$ & 0.007 & $0.31(0.13-0.74)$ \\
\hline Post-partum & 83 (83.8) & $21(61.8)$ & & \\
\hline \multicolumn{5}{|c|}{ Delivery at a health care facility } \\
\hline Yes & $53(53.5)$ & $12(35.3)$ & 0.066 & $2.11(0.94-4.73)$ \\
\hline No & $46(46.5)$ & $22(64.7)$ & 0.066 & $0.47(0.21-1.05)$ \\
\hline \multicolumn{5}{|l|}{ Fate of newborn } \\
\hline Alive & $31(31.3)$ & $13(38.2)$ & 0.458 & $0.74(0.33-1.67)$ \\
\hline Stillborn & $22(22.2)$ & $4(11.8)$ & 0.185 & $2.14(0.68-6.73)$ \\
\hline Not specified & $4(4)$ & $0(0)$ & 0.233 & \\
\hline \multicolumn{5}{|c|}{ Time elapsed from admission-death (hours) } \\
\hline$<3$ & $29(29.3)$ & $2(5.9)$ & 0.005 & $6.63(1.49-29.5)$ \\
\hline [3 - 24] & $46(46.5)$ & 18 (52.9) & 0.512 & $0.77(0.35-1.68)$ \\
\hline [24 - 48] & $9(9.1)$ & $3(8.8)$ & 1.000 & $1.03(0.26-4.05)$ \\
\hline [48 - 72] & $1(1)$ & $2(5.9)$ & 0.099 & $0.16(0.01-1.82)$ \\
\hline D4 - D6 & $5(5.1)$ & $4(11.8)$ & 0.179 & $0.4(0.1$ - 1.59) \\
\hline$>7$ & $6(6.1)$ & $2(5.9)$ & 1.000 & $1.03(0.2-5.36)$ \\
\hline Not specified & $4(4)$ & $3(8.8)$ & 0.281 & $0.44(0.09-2.07)$ \\
\hline
\end{tabular}

\%: percentage; OR: Odds Ratio; CI: confidence interval.

Table 5. Medical causes of maternal death at YCH and BRH. 2010-2014.

\begin{tabular}{|ccccc}
\hline & YCH & BRH & & \\
Causes of death & $\mathbf{N}=\mathbf{9 9}$ & $\mathbf{N}=$ & P value & OR (CI) \\
\cline { 2 - 4 } & $\mathbf{N}(\%)$ & $25(73.5)$ & 0.371 & $1.52(0.6-3.84)$ \\
\hline Direct causes & $72(72.7)$ & $12(35.3)$ & 0.406 & $1.41(0.63-3.16)$ \\
Hemorrhage & $43(43.4)$ & $6(17.6)$ & & $0.740 .41-3.55)$ \\
Infections & $8(23.5)$ & $5(14.7)$ & & $2.02(0.64-6.37)$ \\
Hypertensive disease & $17(17.2)$ & $2(5.9)$ & 0.224 & \\
Others & $4(4)$ & $4(11.8)$ & & \\
Indirect causes & $21(21.2)$ & $5(14.7)$ & & \\
Not specified & $6(6.1)$ &
\end{tabular}

\%: percentage; OR: Odds Ratio; CI: confidence interval. 


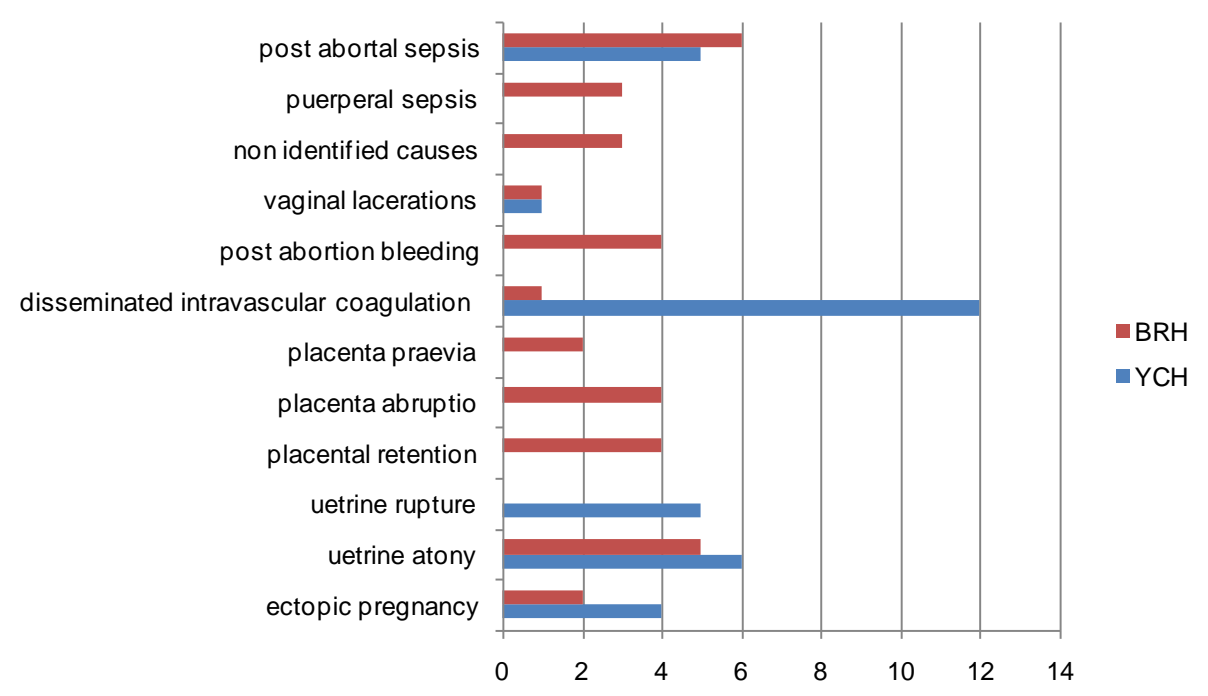

Figure 1. Direct causes of maternal death.

Adolescents accounted for $9 \%$ of maternal deaths, $8.1 \%$ at $\mathrm{YCH}$ and $11.8 \%$ at BRH. Financial constraints and single parenthood favor unsafe abortions and their consequences. Failure to receive antenatal care can result in the death of pregnant adolescents.

Most of the causes of death were direct, $72.7 \%$ and $73.5 \%$ at $\mathrm{YCH}$ and BRH, respectively. As with other authors hemorrhage is the first cause of death [13]. At the top of the list of causes were hemorrhage (43.4\%) and hypertensive diseases (35.5\%) at YCH, whereas at BRH hemorrhage topped the list (35.5\%), followed by infection (17.6\%) and hypertensive diseases (14.7\%). Death due to septic abortion occurred in $10.5 \%$ of cases. Induced abortions and illicit providers are responsible for this finding.

Indirect causes of death occurred in $18.8 \%$ of cases. These included, at the forefront, anemia, meningitis and complications of AIDS. Other authors found similar rates [10]. The high frequency of anemia in malariaendemic areas make it a likely cause since sub-optimal hemoglobin levels can become critical, in addition to anemia decreasing one's ability to fight infection. TEBEU et al. [5] showed that anemia caused death in $12.7 \%$ of cases. Anemia prior to delivery increases the risk of death 4 to 6 fold [9] [12].

Some limits of this study should be considered. It was a retrospective study that used medical records that were filled in emergency situations in a system with a sub-optimal archival services for medical records. We included only deaths which occurred in the maternities. For these reasons, some selection bias has to be considered. While MMR is likely underestimated, our findings can certainly be used to explore this subject in both hospitals.

\section{Conclusion}

Our results showed that although seen in different proportions, the causes of maternal mortality are the same and will remain thus. The contextual causes are however different, dominated in Bamenda by abortion related complications and in Yaoundé by financial constraints and lack of blood products. We recommend a review of the health delivery system through the improvement of accessibility and affordability to healthcare, as well as the introduction of a health insurance scheme to ensure prompt management of emergency cases. And finally, the creation of blood transfusion system with a national policy for donors will contribute to a quicker access to blood transfusion.

\section{Conflict of Interest}

The authors declare no conflict of interests.

\section{Authors' Contributions}

Nana P.J,. Medoua KKES, Dohbit J. conceived the study, participated in the study design and collection data. 
Essiben F. has been involved in analysis and interpretation of data and drafting the manuscript. Lifanji Morfaw, Eko F. and Esiene A. participated in data collection and review of the article. Mbu R. supervised the study. All authors have read and approved the final manuscript.

\section{Acknowledgements}

The authors thank the administrative personnel of the Yaoundé Central Hospital and the Bamenda Regional Hospital for facilitating the implementation of this study as well as staff of the service and personnel of the maternity for their support during the data collection. Apart from the personal contribution of each author, the study was not funded.

\section{References}

[1] WHO (2015) Maternal Mortality. Fact Sheet No348. http://www.who.int/mediacentre/factsheets/fs348/en/

[2] INED (French Institute for Demographic Studies). Maternal Mortality in the World. (In French). https://www.ined.fr/fr/tout-savoir-population/memos-demo/fiches-pedagogiques/la-mortalite-maternelle-dans-le-mond el

[3] National Institute of Statistics of Cameroon. Health Statistics of Cameroon (2012) Chapter 29: Cameroon in Africa. http://www.stat.cm/downloads/annuaire/2012/Annuaire-2012-chapitre-29.pdf

[4] National Institute of Statistics of Cameroon, ICF International Compagny, 2011 (2012) Demographic and Health Survey and Multiple Indicators Cluster Survey DHS-MICS201: Final Report September 2012. (In French). http://www.cnls.cm/docs/Rapport_EDS_2011_au_Cameroun.pdf

[5] Tebeu, P.M., Ngassa, P., Kouam, L., Major A.L. and Fomulu, J.N. (2007) Maternal Mortality in Maroua Provincial Hospital, Cameroon (2003-2005). West Indian Medical Journal, 56, 502-507.

[6] Agan, T.U., Archibong, E.I., Ekabua, J.E., Ekanem, E.I., Abeshi, S.E., Edentekhe, T.A. and Bassey, E.E. (2010) Trends in Maternal Mortality at the University of Calabar Teaching Hospital, Nigeria, 1999-2009. International Journal of Women's Health, 2, 249-254. http://dx.doi.org/10.2147/IJWH.S11971

[7] Okonofua, F.E., Abejide, A. and Makanjuola, R.A. (1992) Maternal Mortality in Ile-Ife, Nigeria: A Study of Risk Factors. Studiesin Family Planning, 23, 319-324. http://dx.doi.org/10.2307/1966529

[8] Maine, D. (1991) Safe Motherhood Progress, Options and Issues. Columbia University Center for Population and Family Health, New York.

[9] Bedi, N., Kambo, I., Dhillon, B.S., et al. (2001) Maternal Deaths in India: Preventable Tragedies. (An ICMR Task Force Study). Journal of Obstetrics and Gynecology of India, 51, 86-92.

[10] Pratima, D.K., Manglem, S. and Randhoni, D.S. (2012) Maternal Mortality and Its Causes in a Tertiary Center. Journal of Obstetrics and Gynaecology of India, 62, 168-171. http://dx.doi.org/10.1007/s13224-012-0169-1

[11] Fomulu, J.N., Ngassa, P.N., Nong, T., Nana, P. and Nkwabong, E. (2009) Maternal Mortality at the Maternity of the University Hospital Center Yaoundé, Cameroon: A 5 Years Retrospective Study (2002-2006). Health Sciences and Diseases, 10. http://www.hsd-fmsb.org/index.php/hsd/article/viewFile/48/pdf_127

[12] Tort, J., Rozenberg, P., Traoré, M., Fournier, P. and Dumont, A. (2015) Factors Associated with Postpartum Hemorrhage Maternal Death in Referral Hospitals in Senegal and Mali: A Cross-Sectional Epidemiological Survey. BMC Pregnancy and Childbirth, 15, 235. http://dx.doi.org/10.1186/s12884-015-0669-y

[13] Say, L., Chou, D., Gemmill, A., Tunçalp, Ö., Moller, A.B., Daniels, J., Gülmezoglu, A.M., Temmerman, M. and Alkema, L. (2014) Global Causes of Maternal Death: A WHO Systematic Analysis. Lancet Global Health, 2, e323-333. http://dx.doi.org/10.1016/S2214-109X(14)70227-X 